\title{
Oscillatory Brain Activity in the Time Frequency Domain Associated to Change Blindness and Change Detection Awareness
}

\author{
Álvaro Darriba ${ }^{1}$, Paula Pazo-Álvarez ${ }^{1}$, Almudena Capilla ${ }^{2,3}$, \\ and Elena Amenedor
}

\begin{abstract}
Despite the importance of change detection (CD) for visual perception and for performance in our environment, observers often miss changes that should be easily noticed. In the present study, we employed time-frequency analysis to investigate the neural activity associated with $\mathrm{CD}$ and change blindness (CB). Observers were presented with two successive visual displays and had to look for a change in orientation in any one of four sinusoid gratings between both displays. Theta power increased widely over the scalp after the second display when a change was consciously detected. Relative to no-change and $\mathrm{CD}, \mathrm{CB}$
\end{abstract}

\section{INTRODUCTION}

The ability to detect changes is central for visual perception and for performance in our environment. However, sometimes observers fail to see the changes that should be easily noticed. This phenomenon is known as change blindness (CB; Rensink, O'Regan, \& Clark, 1997) and reveals that the conscious representation of our visual surroundings presents important limitations. Given that the same unnoticed changes can be readily detected once attention is drawn to them, it has been suggested that attention is crucial to change awareness (Landman, Spekreijse, \& Lamme, 2003; O’Regan, Rensink, \& Clark, 1999; Rensink et al., 1997). This hypothesis is supported by findings showing that changes are more likely to be detected when they take place in objects that, because of their salience or semantic relevance, receive preferential attention in a scene. fMRI studies indicating that activity in brain networks involved in the control of attention correlates with conscious change detection (CD) provide further support to this claim (Pessoa \& Ungerleider, 2004; Beck, Rees, Frith, \& Lavie, 2001).

Attention can be engaged via either bottom-up or topdown mechanisms. Under normal circumstances, changes in visual scenes usually produce motion transients, which automatically capture attention in a bottom-up way and

${ }^{1}$ University of Santiago de Compostela, ${ }^{2}$ Autonoma University of Madrid, ${ }^{3}$ University of Glasgow was associated with a pronounced theta power enhancement at parietal-occipital and occipital sites and broadly distributed alpha power suppression during the processing of the prechange display. Finally, power suppressions in the beta band following the second display show that, even when a change is not consciously detected, it might be represented to a certain degree. These results show the potential of time-frequency analysis to deepen our knowledge of the temporal curse of the neural events underlying $\mathrm{CD}$. The results further reveal that the process resulting in $\mathrm{CB}$ begins even before the occurrence of the change itself.

facilitate the conscious detection of the change. However, when these transients are absent or masked by their simultaneous occurrence with visual disruptions such as blank intervals (Rensink et al., 1997), eye blinks (Rensink, 2000), saccades (Grimes, 1996), or "mudsplashes” (O'Regan et al., 1999), even prominent and previously anticipated changes can go undetected (Rensink, 2000). Under such circumstances, change awareness is thought to rely on the efficiency of voluntary (top-down) attention mechanisms actively looking for a change within the postchange scene (Simons, 2000). This search requires a comparison process between the pre- and postchange displays in which observers must have represented the original scene in enough detail to notice that something has changed. Therefore, $\mathrm{CB}$ could have different causes and affect different stages of the processing of a visual scene. A deficient or inadequate memory encoding of any of the two displays or a failure in the comparison process itself in spite of both scenes being represented in detail may lead to CB (Simons, 2000). Consequently, attention deployment on each display would be critical for $\mathrm{CD}$, as it would be needed to encode the identity of objects in memory across time (Rensink et al., 1997). However, several studies have pointed out that attention may not guarantee CD (O'Regan, Deubel, Clark, \& Rensink, 2000; Levin \& Simons, 1997). The mode in which observers employ their top-down resources, which as such are volitive and could vary as a function of their interests or strategies, must be adequate for the task performed. Most 
CB paradigms differ from everyday conditions in that observers usually know that a change is about to occur and apply top-down resources to its detection. This particularly affects the way in which the prechange scene is observed. Attention facilitates both the memory encoding of the prechange scene and the reading of its trace to compare it with the changed display. According to CB models (Rensink, 2000), little visual information is usually encoded as we observe our environment. Thus, in the absence of transient signals, an unexpected change could only be consciously detected if it occurred in an object that has previously captured attention and has subsequently been encoded into memory. In CB experiments, however, observers deliberately attempt to encode the prechange scene into their working memory (WM) in the best possible way, as this representation must be held and compared with the changed scene. Changes in objects that have not been encoded may pass unnoticed. Because WM capacity is limited and the prechange display may not be available for sufficient amount of time to allow a thorough encoding of it, the mode in which resources are applied on the prechange scene may be critical for CD.

However, most of the studies have restricted their interest to the processes involved once the change has already occurred. Because many of them have relied on behavioral measures, the role of the activity related to the processing of the prechange display remains largely unknown. Analysis of overt behavior is limited by the fact that participants' response is the final output of a series of cognitive processes, and behavioral measures alone cannot distinguish between them. This is also partially true for hemodynamic measures. In recent years, several neuroimage studies have provided important insight into the CB phenomenon by showing the involvement of brain areas commonly associated with the control of attention in the CD process (Pessoa \& Ungerleider, 2004; Beck et al., 2001). These findings have been later supported by evidence from TMS (rTMS) experiments (Beck, Muggleton, Walsh, \& Lavie, 2006) and have largely contributed to stress the role of attention in CD. However, the limited temporal resolution of these techniques does not provide precise information about the time course of the CD process, so conclusions on the role of the activity associated to the processing of the prechange scene cannot be drawn.

Electrophysiological measures (ERPs, ERP), which overcome these restrictions by virtue of their high temporal resolution, have found electrophysiological indices of CD (Pourtois, De Pretto, Hauert, \& Vuilleumier, 2006; Eimer \& Mazza, 2005; Koivisto \& Revonsuo, 2003, 2005), but only a few works have included into their analysis of the activity related to the processing of the prechange display (Pourtois et al., 2006; Koivisto \& Revonsuo, 2005). Although these studies provide some indication about how this activity may affect the CD process, their results are in disagreement with each other, so the issue of prechange activity remains an open question.

The present study was conducted to shed further light on the processes responsible for $\mathrm{CB}$ and, in particular, on the role of the activity previous to the occurrence of a change. In the main experiment, we recorded EEG while participants performed a one-shot CD task (Phillips, 1974) wherein each trial consisted of a sequence of two successive displays, each with four sinusoidal gratings, separated by a blank screen. The change, when present, consisted of any of the gratings changing its orientation. We included into the analyses the whole sequence of stimuli, with the purpose of gaining insight into the time course of neural events underlying CB and CD. In addition, time-frequency (TF) analysis was used to achieve a more complete description of those events. In classic time-amplitude analysis, stimulus-induced activities, which appear with a jitter in latency from one trial to the next, tend to disappear when averaged. Thus, only evoked activities, phase-locked to a stimulus, remain available for analysis. TF analysis, in which power is computed on each single trial and then averaged, provides information on both evoked and induced activities (Tallon-Baudry \& Bertrand, 1999).

A second goal of this experiment was to investigate the question of implicit CD. This term refers to the notion of changes in the environment being implicitly represented by the visual system, even when observers report not to have perceived them. Several studies have shown evidence of unaware changes influencing subsequent behavior. However, with a few exceptions (Kimura, Katayama, \& Ohira, 2008; Laloyaux, Destrebecqz, \& Cleeremans, 2006; Fernandez-Duque, Grossi, Thornton, \& Neville, 2003), most electrophysiological studies have not found any marker of implicit CD (Pourtois et al., 2006; Eimer \& Mazza, 2005; Koivisto \& Revonsuo, 2003).

In addition, to clarify the meaning of the modulations in the oscillatory activity found in the main experiment, we recorded the EEG from a subset of the original group of participants while they performed a modified version of the CB task that included two different WM load conditions. On each trial they were presented with a brief bilateral array of gratings and were asked to look for a change in only one hemifield, which was indicated with an arrow. The details of this experiment are explained in more detail below.

\section{EXPERIMENT 1}

\section{Methods}

\section{Participants}

Thirty right-handed healthy volunteers gave their written consent to participate in the experiment and received monetary compensation for their participation. Nine participants were disregarded because of an insufficient number of trials in some conditions, which lead to an unacceptable signal to noise ratio. Thus, 21 participants (eight men, mean age $=24.67$ years, $S D=5.34$ years, range $=$ 19-34 years) remained in the sample. All of them reported no history of neurological or psychiatric disorders and having normal or corrected-to normal vision. 


\section{Stimuli and Procedure}

Participants were seated in an electrically shielded, sound attenuated, and dimly lit room at a viewing distance of $100 \mathrm{~cm}$ from a 21 -in. video CRT monitor $(1024 \times 768$ at $70 \mathrm{~Hz}$ ), with a response pad under their hands. Stimuli consisted of displays containing four sinusoidal gratings ( $25 \%$ contrast, $2.6 \mathrm{cpd}, 1^{\circ}$ visual angle, $3.5 \mathrm{~cd} / \mathrm{m}^{2}$ ), each one oriented either vertically or horizontally, displayed on a gray background $\left(2.85 \mathrm{~cd} / \mathrm{m}^{2}\right)$, and located at a distance of $5^{\circ}$ from a central fixation cross, which subtended $0.5^{\circ} \times 0.5^{\circ}$. The fixation point remained continuously present until the second display disappeared.

We employed a one-shot CD paradigm (Phillips, 1974). On each trial, two displays (S1, S2) were presented successively for 133 msec each and separated by an empty interval of $665 \mathrm{msec}$. The experiment consisted of 20 blocks, with 32 trials per block. On 16 trials per block, both displays were identical (no-change trials). On the remaining 16 trials, any one of the four gratings was replaced by a $90^{\circ}$ rotated grating, whereas the other three remained identical across displays (change trials). Changes on any item occurred in random order and with equal probability. Change and no-change trials were randomly intermingled. Stimuli display and behavioral response collection were carried out using Presentation software.

Participants were given verbal instructions to maintain their gaze on the central fixation cross and to report whether they had noticed a change between the two displays by pressing the key under their left or right hand at the end of each trial, when a question mark appeared on the screen. This led to four potential conditions: $\mathrm{CD}, \mathrm{CB}$, no-change correct (NCC), and false alarm (FA). Assignment of response buttons was counterbalanced across subjects. After this response was given, a four-point scale appeared on the screen asking subjects about the confidence degree they had in their response (low, mediumlow, medium-high, and high). Participants answered by pressing one of four keys in their response pad. Intertrial interval was $2000 \mathrm{msec}$. Before carrying out the task with simultaneous ERP recording, subjects performed some test trials to check that they understood instructions correctly. Participants were allowed short, self-paced breaks between blocks.

\section{Electrophysiological Recording}

Continuous EEG data (0.05-100 Hz bandpass; $50 \mathrm{~Hz}$ notch filtered) were collected using BrainAmp amplifiers (Brain Products, Munich, Germany) from 60 scalp sites using sintered $\mathrm{Ag}-\mathrm{AgCl}$ electrodes mounted on an elastic cap (EASYCAP, Herrsching-Breitbrunn, Germany) at a sampling rate of $500 \mathrm{~Hz}$ with a 10-k amplification. EEG electrodes were placed following the extended 10-20 position system (Fp1, Fp2, AF7, AF3, AFz, AF4, AF8, F7, F5, F3, F1, Fz, F2, F4, F6, F8, FT7, FC5, FC3, FC1, FCz, FC2, FC4, FC6, FT8, T7, C5, C3, C1, Cz, C2, C4, C6, T8, TP7, CP5, CP3, CP1,
CPz, CP2, CP4, CP6, TP8, P7, P5, P3, P1, Pz, P2, P4, P6, $\mathrm{P} 8, \mathrm{PO} 7, \mathrm{PO} 3, \mathrm{POz}, \mathrm{PO} 4, \mathrm{PO} 8, \mathrm{O} 1, \mathrm{Oz}, \mathrm{O} 2)$ and were referenced to the tip of the nose. Four additional electrodes were placed above and below the left eye and on the outer canthi of both eyes to monitor blinks and eye movements. A single ground electrode was attached at the nasion. Sensor impedances were kept below $10 \mathrm{k} \Omega$.

\section{Spectral Analysis of the Oscillatory Activity}

Data from all conditions were epoched into segments of $4198 \mathrm{msec}$ ( -1500 to $2698 \mathrm{msec}$ relative to S1 presentation) and merged together for each subject. Before the spectral analyses, artifacts were removed using EEGLAB v6.0b (Delorme \& Makeig, 2004), a freely available open source software toolbox (Swartz Center for Computational Neurosciences, La Jolla, CA; www.sccn.ucsd.edu/ eeglab) running under Matlab 7.5 (MathWorks, Inc., Natick, $\mathrm{MA}$ ) in the following way. First, epochs containing nonstereotyped artifacts (e.g., cable movement, swallowing) were manually removed, whereas epochs containing repeatedly occurring, stereotyped artifacts (e.g., eye blinks, muscle artifact, etc.) were kept. Then, extended infomaxindependent component analysis (ICA; Lee, Girolami, \& Sejnowski, 1999; Bell \& Sejnowski, 1995) was applied individually for each subject, using a weight change of $<10^{-7}$ or 512 iterations as a stop criterion. Component activations were subsequently assessed and categorized as brain activity or nonbrain artifact (e.g., muscle, electrode artifact, or eye movement activity) by visual inspection based on their scalp topographies, time courses, ERP image, and activation spectra. After identification of components constituting artifacts, individual EEG data containing all conditions were reconstructed without those components. Finally, epochs corresponding to each experimental condition were extracted from ICA-pruned data for each subject.

To make comparisons between conditions, the number of trials containing a correct response (CD, NCC) was adjusted for each subject to be similar to that containing CB. Trials on those conditions were randomly selected. This procedure resulted in 96.9 trials per condition for each subject on average. Owing to its particularly low rate, the FA condition was discarded from subsequent analyses, as it was not possible to have a number of trials for every participant comparable to that from the other three conditions.

All the subsequent TF analyses were performed using also the EEGLAB software. Spectral changes in oscillatory activity were analyzed using a wavelet transform, which provides a good compromise between time and frequency resolution (Tallon-Baudry \& Bertrand, 1999). Trial-by-trial $\mathrm{TF}$ analysis was computed for every subject, condition, and sensor separately by a Morlet wavelet transform with linearly increased cycles (Delorme \& Makeig, 2004), from two cycles for the lowest frequency $(2 \mathrm{~Hz})$ to 15 cycles for the highest frequency $(30 \mathrm{~Hz})$ analyzed (step size, $0.5 \mathrm{~Hz}$ ). 
Changes in event-related spectral power response were computed by the Event-Related Spectral Perturbation (ERSP) index (Delorme \& Makeig, 2004). Significant changes in ERSP are reflected by mean TF power values that exceed the significant cut-off threshold extracted from the baseline period. To determine the threshold significance of ERSP, bootstrap distributions $(p<.01)$, extracted randomly from baseline data $(-1500 \mathrm{msec})$ and applied 200 times, were used (Delorme \& Makeig, 2004).

\section{Statistical Analyses of Oscillatory Activity}

Statistical analyses were carried out on a time interval ranging from 0 to $1600 \mathrm{msec}$ relative to the onset of S1 and divided for analysis purposes in 26 time windows of equal length (approximately $60 \mathrm{msec}$ each). Neighboring electrodes were combined into topographical ROIs to keep statistical power (Oken \& Chiappa, 1986).

To differentiate the activity related to $\mathrm{CD}$ from that related to $\mathrm{CB}$, we compared trials containing a change as a function of whether participants reported to be aware of it (CD trials) or reported not to have seen it (CB trials). These two types of trials differ with respect to participants' reported change awareness but are equivalent with respect to the actual occurrence of a change. Thus, differences between these trials might reflect neural processes responsible for CD (Eimer \& Mazza, 2005). To ensure that these differences were not simply because of the production of a correct response, we also included trials where observers correctly reported that no change had occurred (NCC trials). This also allowed us to explore the possible existence of implicit CD by comparing CB and NCC trials, which are equivalent with respect to the participants' reported change unawareness but different with respect to the physical presence of a change.

Time and frequency windows chosen for the analyses were selected based on the bootstrap distributions figures previously used to determine the significance of the ERSP measures (Digiacomo, Marco-Pallarés, Flores, \& Gómez, 2008). Two-factor repeated measures ANOVAs were performed on each TF window, with "condition" (CD, CB, NCC) and "electrode" (frontal-central including F3/4, Fz, FC3/4, and FCz; frontal-parietal including F3/4, Fz, FC3/4, $\mathrm{FCz}, \mathrm{P} 3 / 4$, and Pz; and parietal-occipital including PO7/8, $\mathrm{O} 1 / 2$, and $\mathrm{Oz}$ ) as factors (Kiebel, Tallon-Baudry, \& Friston, 2005). This analysis included all participants' pooled trials under the three different conditions. $p$ values were calculated by using the Greenhouse-Geisser correction when appropriate. All comparisons were Bonferroni corrected.

\section{Event-related Potentials Analyses}

For ERP analysis, the ICA-corrected epochs were low-pass filtered at $20 \mathrm{~Hz}$ with a finite impulse response filter and averaged. The baseline was designated from -100 to 0 msec. Differences between conditions were analyzed by comparing mean amplitude values in selected time windows (90-130 msec for P1, 160-200 msec for N1, and 480-800 for P3) at adjacent electrode positions. Repeated measures ANOVAs were performed using a GreenhouseGeisser correction for nonsphericity when required. Bonferroni adjustment was applied to the comparisons.

\section{Horizontal EOG Analyses}

Fixation at the center of the screen was continuously monitored by horizontal EOG (HEOG) during execution of the peripheral CD task. To check whether EOG significant effects could be observed among conditions that could potentially add eye-movement-related artifacts to the data, additional analyses were performed. For each condition, we calculated the average eye position measured by the horizontal EOG during 18 successive bins of $100 \mathrm{msec}$ from 0 to 1800 msec post-S1 onset that covered the whole trial (S1, ISI blank, S2). A repeated measures ANOVA with two factors: Condition (3) $\times$ Time bins (18) was conducted on these data.

\section{Results}

\section{Behavioral Results}

Overall, our task was successful in achieving an adequate proportion of trials where a change was missed (CB rate $=$ $32.39 \%$ ), whereas FAs remained relatively rare when no change occurred (17.07\%). These results allowed us to have, for each condition of interest (CD, CB, NCC), a number of trials sufficient to perform the subsequent TF analyses and make comparisons between conditions. As established before, FA condition was not included into analyses because the number of trials available was too small. To ascertain that there were no significant differences between conditions in relation to the confidence ratings, three-factor repeated measures ANOVA [Change (change/no-change), Response (correct/incorrect), Confidence (high, medium-high, medium-low, low)] was performed on behavioral data. Results from this ANOVA showed neither significant main effect of the factor Confidence $[F(3,60)=0.851, p=.471)]$ nor significant interactions between factors Change $\times$ Confidence $[F(3,60)=$ $0.801, p=.498)]$ or Response $\times$ Confidence $[F(3,60)=$ $1.898, p=.097]$. Because no differences were found and separating the trials for each condition in relation to the degree of confidence would lead to excessive fragmentation of the data, confidence ratings were not included as a factor in subsequent ERP and TF analyses.

\section{TF Results}

Figure 1 shows the TF spectra averaged across subjects at midline electrodes $\mathrm{Fz}, \mathrm{Cz}, \mathrm{Pz}$, and $\mathrm{Oz}$ for the three conditions under study (CD, CB, NCC). The grand-average ERPs are shown below the TF plots corresponding to Fz and $\mathrm{Oz}$ positions. 


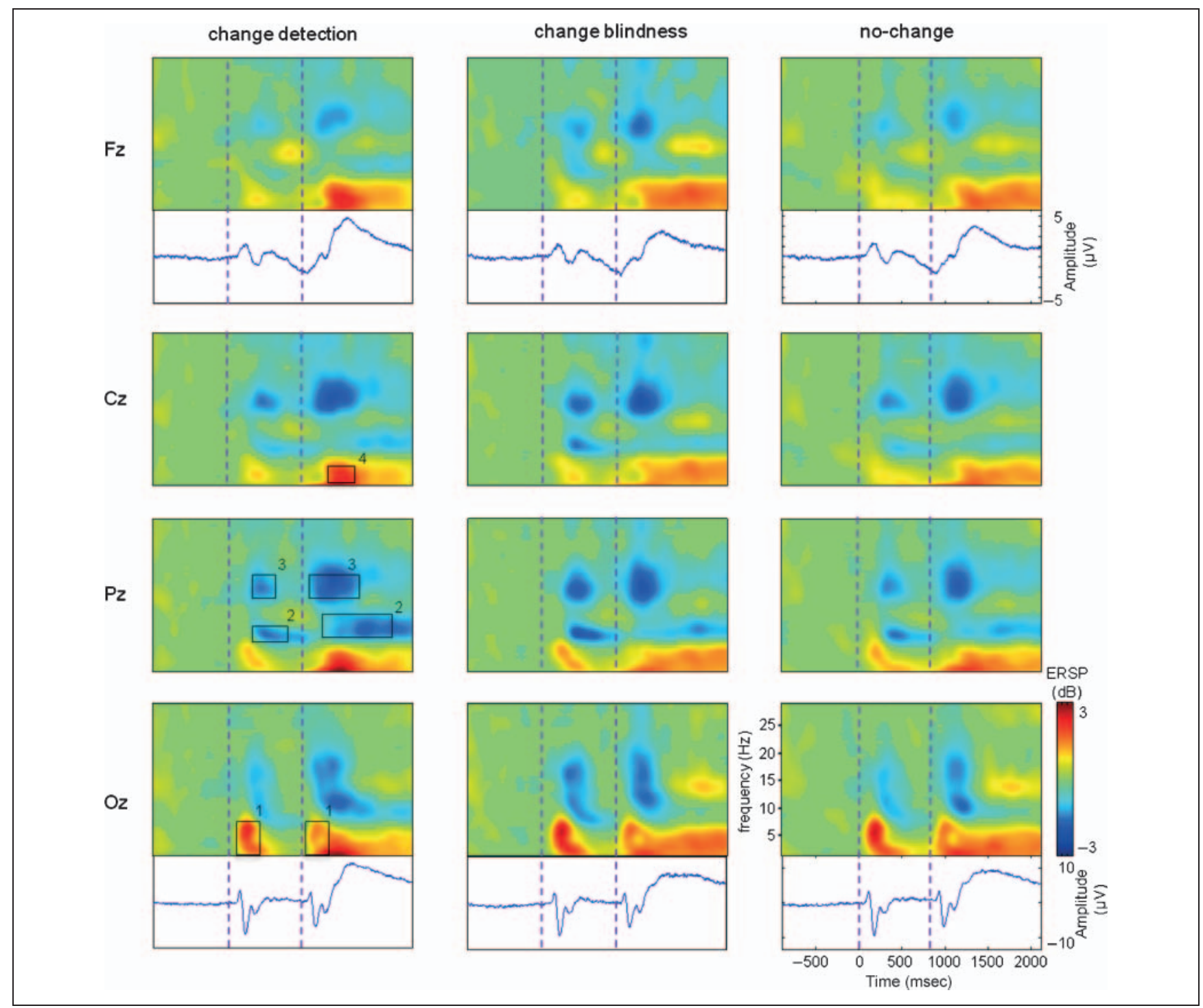

Figure 1. TF analysis in a 2- to $30-\mathrm{Hz}$ frequency range at midline electrodes $\mathrm{Fz}, \mathrm{Cz}, \mathrm{Pz}$, and $\mathrm{Oz}$, grand-averaged across subjects. Results are baseline corrected $(-1500$ to $0 \mathrm{msec}$ ), producing negative and positive values (areas in blue and red, respectively). There is a transient theta component $(3-8 \mathrm{~Hz})$ of largest power at Oz, following the presentation of S1 (50-375 msec post-S1) and S2 (50-375 msec post-S2) (1). There are also power suppressions in the alpha $(8-15 \mathrm{~Hz})(2)$ and lower beta $(15-20 \mathrm{~Hz})(3)$ bands following the presentation of both S1 and S2 displays. These reductions are transient in the beta band (150-500 msec post S1 and 150-500 msec post-S2) at every location, but they are more sustained in the alpha band, especially at central and parietal locations. Finally, a sustained power increase in the theta band can be seen starting 300 msec after the onset of S2 and lasting until the end of the epoch (4). ERP waveforms corresponding to positions Fz and Oz sites are represented under their respective TF images.

The representation of TF power averaged across single trials showed the existence of a broadly distributed transient power increase in the theta range $(3-8 \mathrm{~Hz})$ following the presentation of both $\mathrm{S} 1(\approx 50-375 \mathrm{msec}$ post-S1) and S2 $(\approx 50-375 \mathrm{msec}$ post-S2). Also in response to the presentation of each display, results showed power suppressions in the alpha and lower beta bands $(8-20 \mathrm{~Hz}, \approx 150-$ 500 msec post-S1 and 8-20 Hz, $\approx 150-500$ msec post-S2) widely distributed over the scalp. Finally, a more sustained power increase was observed in the theta band $(3-8 \mathrm{~Hz})$, beginning approximately $300 \mathrm{msec}$ after the onset of S2 and lasting until the end of the epoch. All these oscillatory components were observed for every condition.
Repeated measures ANOVAs executed on TF windows showed that CB trials began to differ from CD and NCC conditions as early as a few hundred milliseconds after S1 onset, that is, even before the occurrence of a change (see Figure 2). First, a highly significant main effect of Condition was found in the theta band $(3-5 \mathrm{~Hz})$ at posterior locations in two consecutive time windows, $180-242 \mathrm{msec}$ $[F(2,40)=11.51, p=.001]$ and $242-304$ msec post-S1 $[F(2,40)=7.56, p=.002]$ because of more pronounced power enhancement for CB relative to CD and NCC (see Table 1 for Bonferroni post hoc comparisons). No differences were found between these two latter conditions. Second, an equally high significant effect of Condition was 


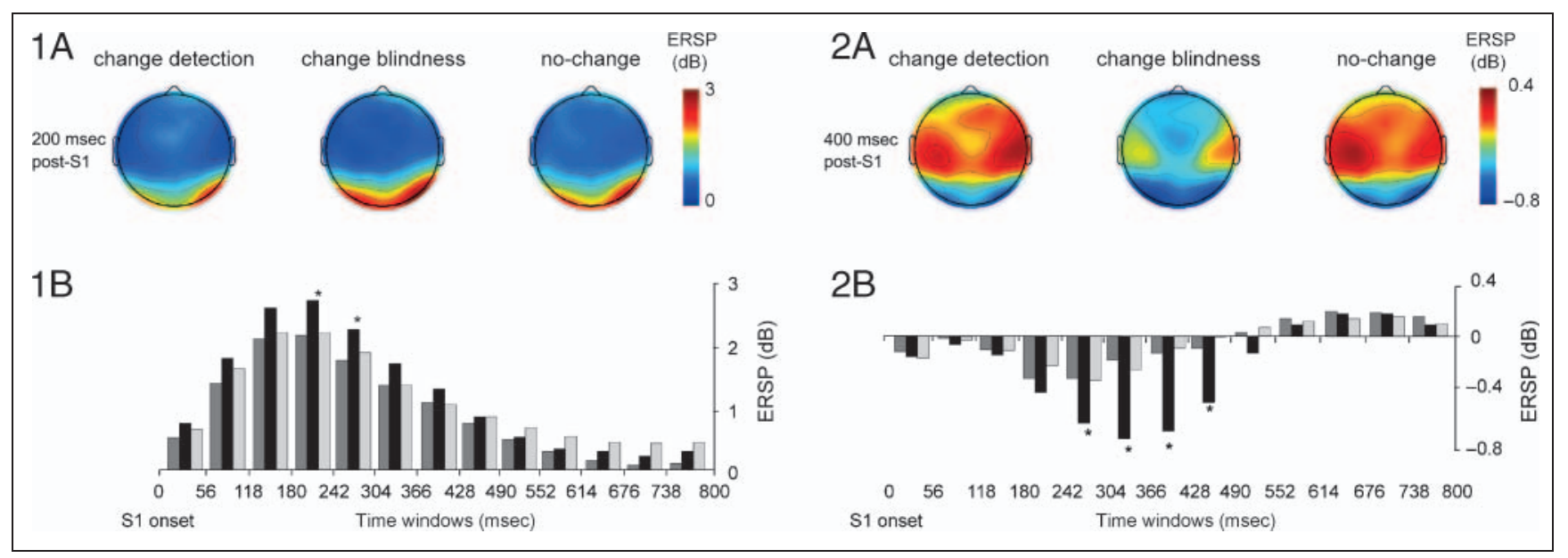

Figure 2. Illustration of the differences found in the prechange theta and alpha bands effects, marked as (1) and (2), respectively, in Figure 1. (1A) Topographic maps of TF energy at $200 \mathrm{msec}$ post-S1 onset averaged across single trials in the $3-5 \mathrm{~Hz}$ frequency range, showing the posterior distribution of the transient theta component, larger in the CB condition. (1B) Estimated marginal means of power for the parietal-occipital electrode cluster (PO7, $\mathrm{PO} 8, \mathrm{O} 1, \mathrm{Oz}, \mathrm{O} 2$ ), in the same frequency range, for the time windows analyzed following the onset of S1. Asterisks indicate the time windows in which power was significantly higher for the CB (black bars) condition than for the CD (dark gray bars) and NCC (light gray bars) conditions. (2A) Topographic maps of TF energy at $400 \mathrm{msec}$ post-S1 onset averaged across single trials in the 13-15 Hz frequency range, showing the frontal-parietal distribution of the transient alpha component (number 2 in Figure 1), larger in the CB condition. (2B) Estimated marginal means of power for the frontal-parietal electrode cluster (F3, Fz, F4, C3, Cz, C4, P3, Pz, P4) in the same frequency range for the time windows analyzed following the onset of S1. Asterisks indicate the time windows in which power was significantly higher for the CB (black bars) condition than for the CD (dark gray bars) and NCC (light gray bars) conditions.

Table 1. Results of the Repeated Measures ANOVAs (Condition $\times$ Electrode) Performed on the TF Data Showing the Main Effect of the Factor Condition on Prechange Theta, Prechange Alpha, Postchange Theta, and Postchange Beta

\begin{tabular}{|c|c|c|c|c|c|}
\hline \multirow[b]{2}{*}{ Prechange Theta } & & \multicolumn{2}{|c|}{$\begin{array}{l}\text { Main Effect } \\
\text { "Condition" }\end{array}$} & \multicolumn{2}{|c|}{ Bonferroni Post hoc Adjustment } \\
\hline & & $F(2,40)$ & $p$ & $\operatorname{ERSP}(C B)>\operatorname{ERSP}(C D)$ & $\operatorname{ERSP}(C B)>\operatorname{ERSP}(N C C)$ \\
\hline \multirow[t]{2}{*}{ PO7, PO8, O1, Oz, O2 (3-5 Hz) } & 180-242 msec post-S1 & 11.51 & $<.001$ & $p<.003$ & $p<.028$ \\
\hline & 242-304 msec post-S1 & 7.56 & $<.002$ & $p<.013$ & $p<.013$ \\
\hline Prechange Alpha & & $F(2,40)$ & $p$ & $E R S P(C B)<E R S P(C D)$ & $\operatorname{ERSP}(C B)<\operatorname{ERSP}(N C C)$ \\
\hline \multirow{3}{*}{$\begin{array}{l}\mathrm{F} 3 / 4, \mathrm{Fz}, \mathrm{C} 3 / 4, \mathrm{Cz}, \mathrm{P} 3 / 4, \mathrm{Pz} \\
\quad(13-15 \mathrm{~Hz})\end{array}$} & $304-366$ msec post-S1 & 7.87 & $<.005$ & $p<.004$ & $p<.017$ \\
\hline & $366-428$ msec post-S1 & 9.64 & $<.003$ & $p<.003$ & $p<.004$ \\
\hline & $428-490$ msec post-S1 & 6.12 & $<.014$ & $p<.033$ & $p<.016$ \\
\hline
\end{tabular}

\begin{tabular}{|c|c|c|c|c|c|}
\hline Postchange Theta & & $F(2,40)$ & $p$ & $\operatorname{ERSP}(C D)>\operatorname{ERSP}(C B)$ & $\operatorname{ERSP}(C D)>\operatorname{ERSP}(N C C)$ \\
\hline \multirow{5}{*}{$\begin{array}{l}\mathrm{F} 3 / 4, \mathrm{Fz}, \mathrm{C} 3 / 4, \mathrm{Cz}, \mathrm{P} 3 / 4, \mathrm{Pz} \\
\quad(3-5 \mathrm{~Hz})\end{array}$} & 304-366 msec post-S2 & 13.04 & $<.001$ & $p<.001$ & $p<.003$ \\
\hline & $366-428$ msec post-S2 & 19.75 & $<.001$ & $p<.001$ & $p<.002$ \\
\hline & 428-490 msec post-S2 & 15.37 & $<.001$ & $p<.001$ & $p<.006$ \\
\hline & 490-552 msec post-s2 & 10.44 & $<.001$ & $p<.001$ & $p<.023$ \\
\hline & $552-614 \mathrm{msec}$ post-S2 & 6.48 & $<.004$ & $p<.003$ & $p<.05$ \\
\hline
\end{tabular}

\begin{tabular}{|c|c|c|c|c|c|}
\hline Postchange Beta & & $F(2,40)$ & $p$ & $E R S P(C D)<E R S P(N C C)$ & $E R S P(C B)<E R S P(N C C)$ \\
\hline F3/4, Fz, FC3/4, FCz (15-17 Hz) & $118-180$ msec post-S2 & 5.38 & $<.034$ & $p<.049$ & $p<.025$ \\
\hline
\end{tabular}

The table shows the $F$ and $p$ values for the main effect of condition (third and four columns), the electrode locations, frequency bands (first column) and time windows (second column) in which these effects were significant, and the post hoc Bonferroni corrected $p$ values for multiple comparisons (fifth and six columns). 
found in the alpha band $(13-15 \mathrm{~Hz})$ at frontal, central, and parietal locations in three consecutive time windows, 304 $366 \mathrm{msec}[F(2,40)=7.87, p=.005], 366-428 \mathrm{msec}[F(2$, $40)=9.64, p=.003]$, and $428-490 \mathrm{msec}[F(2,40)=6.12$, $p=.014]$ post-S1, owing to more pronounced power suppression for CB relative to CD and NCC (see Table 1). Again, no significant differences were found between CD and NCC. This power suppression is in accordance to the typical time course of the alpha power decrease in response to a stimulus, which depends largely on the type of task, frequency band, and stimulation but typically shows a comparatively late onset at about $200 \mathrm{msec}$ poststimulus and a peak around 350-650 msec (Klimesch, Sauseng, \& Hanslmayr, 2007). EEG theta power increase associated with a simultaneous alpha power decrease during the initial stages of information processing have been reported (Gruber, Klimesch, Sauseng, \& Doppelmayr, 2005; Klimesch et al., 2004). Both EEG features have been proved to be sensitive to variations in the amount of resources involved in a task.

S2 onset was followed by more significant differences between conditions. A highly significant main effect of Condition was found in the theta band $(3-5 \mathrm{~Hz})$ at frontal, central, and parietal locations in five consecutive time windows, 304-366 msec $[F(2,40)=13.04, p=.001]$, 366$428 \mathrm{msec}[F(2,40)=19.75, p=.001], 428-490 \mathrm{msec}[F(2$, $40)=15.37, p=.001], 490-552 \mathrm{msec}[F(2,40)=10.44$, $p=.001]$, and 552-614 msec $[F(2,40)=6.48, p=.004]$ post-S2, because of more pronounced power enhancement for CD relative to CB and NCC (see Figure 3 and Table 1). These latter conditions did not differ significantly.

Finally, trials containing a change, whether detected or not, showed a higher power decrease in response to S2 at frontal locations than no-change trials (see Figure 4).
This was reflected by a significant main effect of condition found in a TF window from 15 to $17 \mathrm{~Hz}$ and between 118 and 180 msec post-S2 $[F(2,40)=5.38, p=.034]$ because of more pronounced power decrease for $\mathrm{CD}$ and CB relative to NCC. Post hoc analyses did not reveal differences between CD and CB (see Table 1).

\section{Event-related Potentials Results}

The visual evoked potentials elicited by the first display (S1) were dominated by a positive (P1, $120 \mathrm{msec}$ ) and a negative (N1, $180 \mathrm{msec}$ ) deflection, both prominent at occipital and parietal-occipital electrodes. Similar components emerged after S2 onset, and in this case, they were followed by an additional large positivity (P3, 500$800 \mathrm{msec}$ ), maximal at parietal-occipital sites.

S1-ERP results. For the $\mathrm{P} 1$ and $\mathrm{N} 1$ components evoked by $\mathrm{S} 1$, separate Condition $(\mathrm{CD}, \mathrm{NCC}, \mathrm{CB}) \times$ Hemisphere $($ left, right $) \times$ Electrode $(\mathrm{O} 1 / \mathrm{O} 2, \mathrm{PO} 7 / \mathrm{PO} 8)$ ANOVAs on mean amplitude components did not reveal any significant main effect or interaction involving the factor condition. Therefore, P1 mean amplitude did not differ among conditions at posterior sites (mean values collapsed across four electrodes, $\mathrm{CD}=2.346 \mu \mathrm{V}, \mathrm{CB}=2.106 \mu \mathrm{V}, \mathrm{NCC}=$ $2.333 \mu \mathrm{V}$ ); neither did $\mathrm{N} 1$ component mean amplitude (mean values collapsed across four electrodes, $\mathrm{CD}=$ $-6.219 \mu \mathrm{V}, \mathrm{CB}=-6.465 \mu \mathrm{V}, \mathrm{NCC}=-6.215 \mu \mathrm{V})$.

S2-ERP results. Differences in the $\mathrm{P} 3$ component, approximately $480-800 \mathrm{msec}$ post-S2 onset, were analyzed using ANOVA of Condition $(\mathrm{CD}, \mathrm{CB}, \mathrm{NCC}) \times$ Electrode (occipital, parietal-occipital, parietal) $\times$ Region (left, right, midline). Analyses revealed a significant effect of Condition
Figure 3. Illustration of the differences found in the postchange theta band effect, marked as (4) in Figure 1. (A) Topographic maps of TF energy at $500 \mathrm{msec}$ post-S2 onset averaged across single trials in the 3-5 $\mathrm{Hz}$ frequency range, showing the distribution of the sustained theta component, larger in the CD condition. (B) Estimated marginal means of power for the frontal-parietal electrode cluster (F3, Fz, F4, $\mathrm{C} 3, \mathrm{Cz}, \mathrm{C} 4, \mathrm{P} 3, \mathrm{Pz}, \mathrm{P} 4)$ in the same frequency range for the time windows analyzed following the onset of S2. Asterisks indicate the time windows in which power was significantly higher for CD trials (dark gray bars) than for the CB (black bars) and NCC (light gray bars) trials.

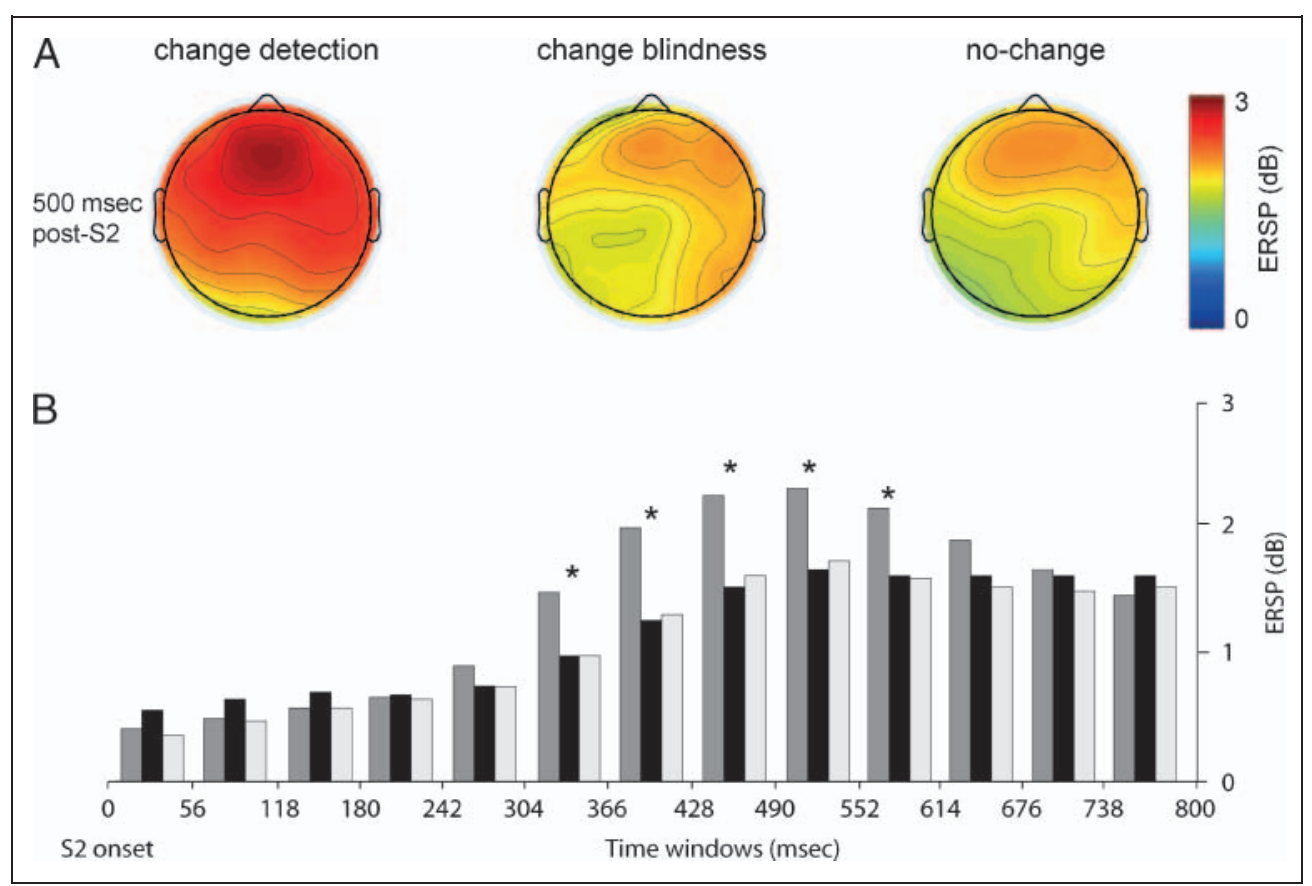


Figure 4. Illustration of the differences found in the postchange beta band effect, marked as (3) in Figure 1.

(A) Topographic maps of $\mathrm{TF}$ energy at $175 \mathrm{msec}$ post-S2 onset averaged across single trials in the $15-17 \mathrm{~Hz}$ frequency range, showing the anterior distribution of the transient beta component (number 3 in Figure 1), larger in the $\mathrm{CD}$ and $\mathrm{CB}$ conditions. (B) Estimated marginal means of power for the frontal electrode cluster (F3, Fz, F4, C3, Cz, C4, P3, $\mathrm{Pz}, \mathrm{P} 4)$ in the same frequency range for the time windows analyzed following the onset of S2. Asterisks indicate the time windows in which power suppression was significantly higher for $\mathrm{CD}$ (dark gray bars) and $\mathrm{CB}$ (black bars) trials than for the NCC (light gray bars) trials.

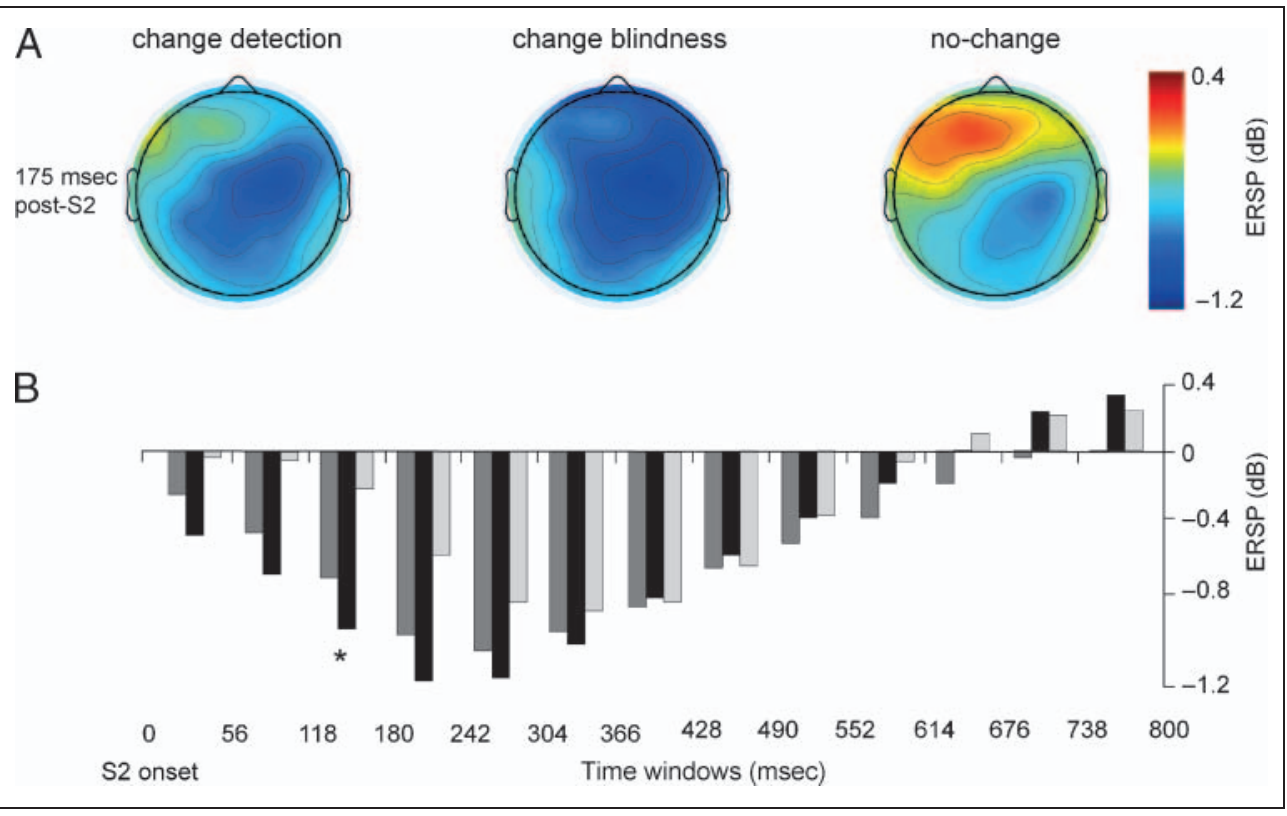

$[F(2,40)=15.383, p=.000]$ because of a larger $\mathrm{P} 3$ for $\mathrm{CD}($ mean $=11.413 \mu \mathrm{V})$ relative to $\mathrm{CB}($ mean $=8.169$; $p=.001$ ) and NCC (mean $=9.411, p=.005$; see Figure 5). Bonferroni post hoc corrected tests revealed that
P3 amplitude was not different between $\mathrm{CB}$ and $\mathrm{NCC}(p=$ .057). Differences in the P3 component at analogous latencies were also observed at central and frontal sites. ANOVAs performed with Condition $(\mathrm{CD}, \mathrm{CB}, \mathrm{NCC}) \times$ Elec-
Figure 5. (A) Scalp maps show the topographic distribution of average potential at latency 1300 msec (500 msec post-S2 onset) for each condition. (B) Grand-averaged ERP waveforms at $\mathrm{Pz}$ location for the $\mathrm{CD}, \mathrm{CB}$, and $\mathrm{NCC}$ conditions. Analyses revealed that post-S2 P3 component amplitude was significantly higher for $\mathrm{CD}$ than for $\mathrm{CB}$ and NCC trials. No differences were found between these latter conditions.

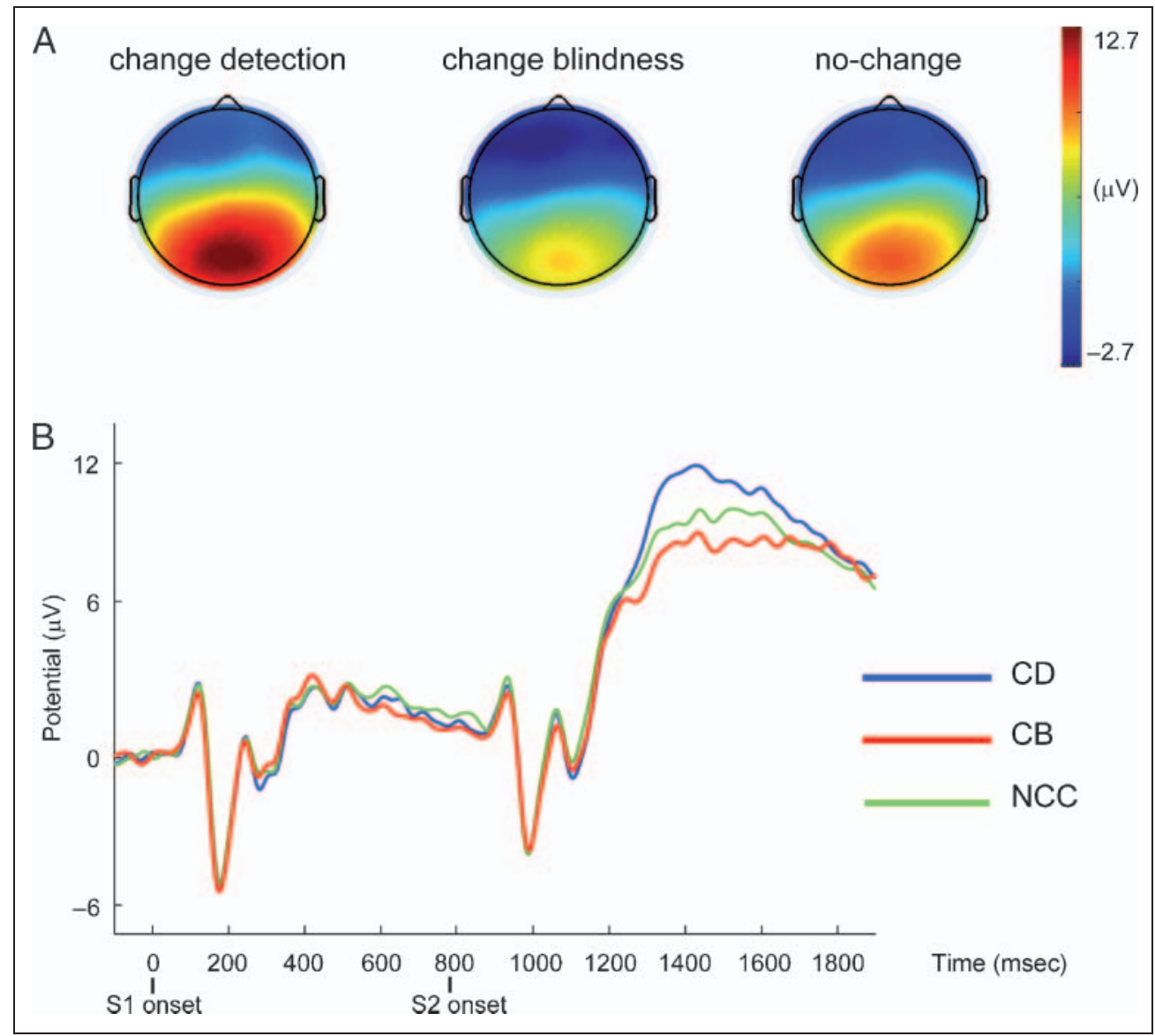


trode (frontal, frontal-central, central) $\times$ Region (left, right, midline) revealed a significant effect of Condition $[F(2$, $40)=9.943 p=.000]$, because of larger amplitudes of CD $($ mean $=6.601)$ compared with $\mathrm{CB}$ condition $($ mean $=$ 4.225). Bonferroni post hoc corrected tests did not reveal significant differences between CD-NCC (NCC mean = $5.223 ; p=.070)$ and $\mathrm{CB}-\mathrm{NCC}(p=.056)$.

HEOG results. Analyses performed on HEOG activity did not reveal any significant effect or interaction (i.e., Condition: $[F(2,40)=.034, p=.967])$, thus indicating that peripheral CD task was performed without any systematic horizontal eye movements.

\section{EXPERIMENT 2}

To further understand the effect that the amount of processing resources applied to the task could have on the results obtained in Experiment 1, we performed a second experiment including two different WM load conditions in which the allocation of the observers' attention was controlled by means of endogenous cues.

\section{Methods}

A subset of eight participants took part in this control test. Stimuli, procedure, electrophysiological recording parameters, and procedures employed for the statistical analyses of the oscillatory activity were similar to those used before but for the following differences. First, in each trial, an endogenous cue (a central arrow lasting for $200 \mathrm{msec}$ ) pointing to one of the visual hemifields (left or right) was presented preceding in $800 \mathrm{msec}$ the onset of S1. Participants were instructed to look for a change in the visual hemifield indicated by the arrow without displacing their gaze from the central fixation point. Second, two different conditions were employed, one in which four items were presented (four-item condition), and another one in which displays contained eight items (eight-item condition). In each trial, half of the gratings were presented in the left and half in the right hemifields. Subjects performed 30 blocks for the eight-item condition and 20 blocks for the four-item condition, with 32 trials per block in both conditions. Third, given that in Experiment 1 the confidence scale did not provide any useful information, it was not included in Experiment 2. Fourth, because of the inclusion of the orienting cue, data were epoched into longer segments (5198 msec, -2500 to $2698 \mathrm{msec}$ relative to S1 onset) to have a baseline period previous to the onset of the cue similar in length to that employed in Experiment 1 (1500 msec). Finally, as long as only CD trials were included into analysis (see next section), repeated measures ANOVAs included "condition" (eight-item, four-item) and "electrode" (frontal-parietal including F3/4, Fz, FC3/4, FCz, P3/4, and $\mathrm{Pz}$ and parietal-occipital including $\mathrm{PO} 7 / 8, \mathrm{O} 1 / 2$, and $\mathrm{Oz}$ ) as factors to establish the differences between conditions.

\section{Results}

\section{Behavioral Results}

Participants' performance was more accurate in the four-item condition (CB rate, four-item: 11.98\%; CB rate, eight-item: 51.36\%). FA rates were low (four-item, 1.69\%; eight-item, 5.97\%), which allowed us to state that participants performed properly in both conditions. The expected small CB rate for the four-item condition prevented us to include $\mathrm{CB}$ trials in subsequent analyses. As a consequence, comparisons in TF analyses were restricted to $\mathrm{CD}$ trials and performed on data sets of approximately 100 trials per condition for each subject.

\section{TF Results}

Figure 6 shows the TF spectra averaged across subjects of the $\mathrm{CD}$ trials at $\mathrm{Oz}$ for the four-item and eight-item conditions, along with a topographic map of TF energy at 200 msec post-S1 onset.

TF plots show similar features to those seen in the main experiment, that is, a broadly distributed transient power increase in the theta range $(3-8 \mathrm{~Hz})$ following the presentation of both S1 (50-375 msec post-S1) and S2 (50375 msec post-S2) and power suppressions in the alpha and low beta bands (8-20 Hz, 150-500 msec post-S1; 8-20 Hz, 150-500 msec post-S2) widely distributed over the scalp, as well as a sustained power increase in the theta band (3-8 Hz) starting about 300 msec after the onset of S2 and lasting until the end of the epoch. All these oscillatory components were observed in the four-item and the eight-item conditions.

ANOVAs showed a significant main effect of condition in the theta band $(3-5 \mathrm{~Hz})$ at posterior locations (PO7, $\mathrm{PO} 8, \mathrm{O} 1, \mathrm{Oz}, \mathrm{O} 2)$ in several consecutive time windows, 130-192 msec $[F(1,7)=28.841, p=.003], 192-252 \mathrm{msec}$ $[F(1,7)=9.312, p=.001]$, and 252-314 msec $[F(1,7)=$ $28.373, p=.003$ ] because of more pronounced power enhancement for the eight-item relative to the four-item condition. Interestingly, these frequency and time ranges are coincident with those in which $\mathrm{CB}$ trials differed from the CD and NCC trials in the main experiment. No significant effects were found in any other band of interest.

\section{DISCUSSION}

People frequently fail to detect changes in their visual environment, even when these changes are expected and observers actively look for them. There have been recurrent proposals that this $\mathrm{CB}$ phenomenon could have different causes and affect different stages of the processing of a visual scene (for an extensive review, see Simons, 2000). However, most of the studies have restricted their interest to the processes involved once the change has already occurred, and little is known about the activity preceding a change and how it could affect the CD process. The aim of the present study was to shed 


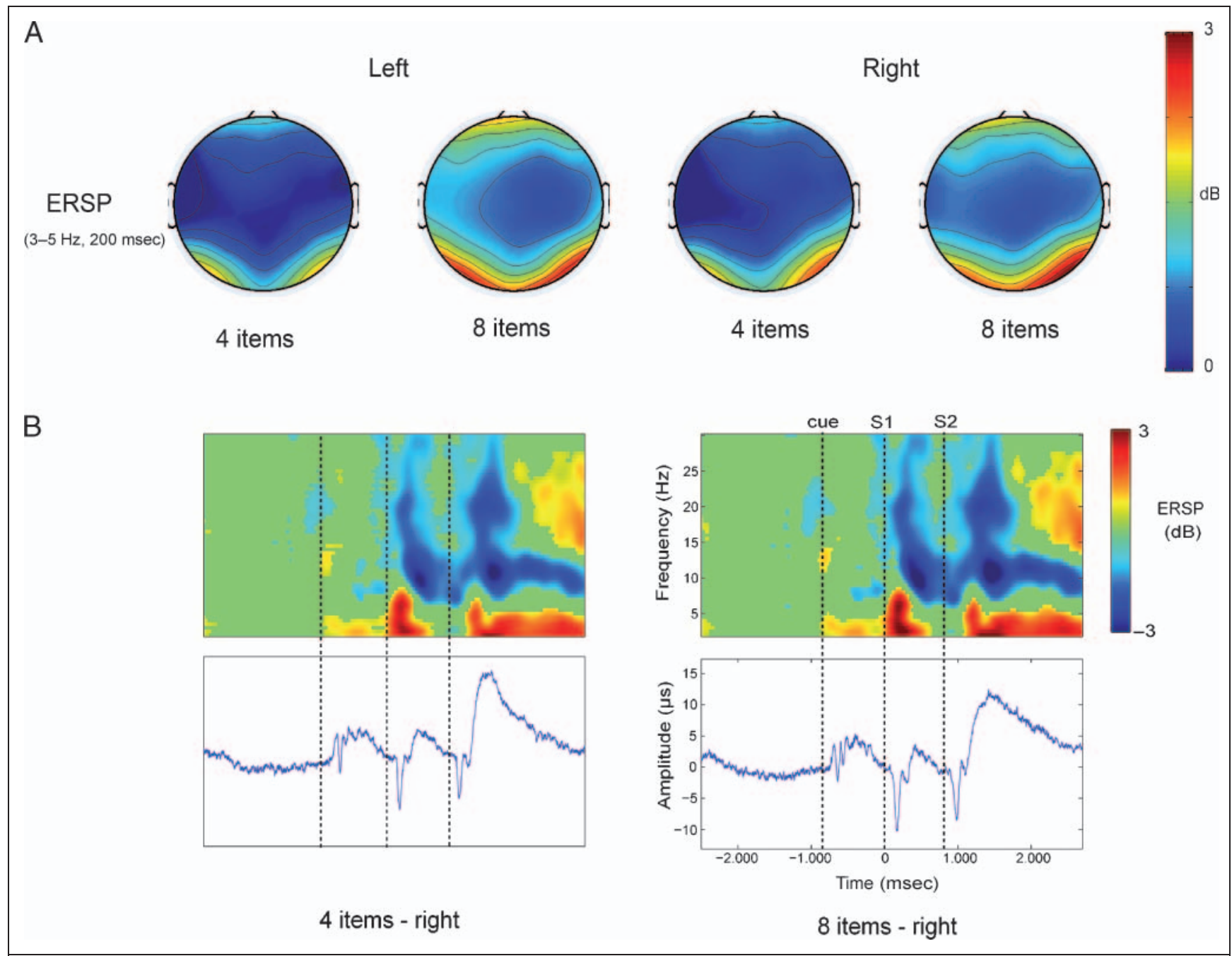

Figure 6. Results found in Experiment 2. (A) Topographic maps display the TF energy at $200 \mathrm{msec}$ post-S1 onset averaged across single trials in the 3- to $5-\mathrm{Hz}$ frequency range, showing the posterior distribution of the transient theta component, larger in the eight-item condition for both left and right changes. (B) TF plots in a $2-30 \mathrm{~Hz}$ frequency range at midline electrode $\mathrm{Oz}$, grand-averaged across subjects, corresponding to changes in the right hemifield for the four-item and eight-item conditions. Results are baseline corrected ( -2500 to $-1000 \mathrm{msec})$, producing negative and positive values (areas in blue and red, respectively). Analyses showed that the power of the transient theta component (3-8 Hz) that follows the presentation of S1 (50-375 msec post-S1) was significantly higher in the eight-item condition.

light on this question. Results indicated that differences in neural oscillatory activity related to the processing of the prechange display could determine whether a change that is about to occur will be detected. These differences are observable in the theta and alpha bands. In addition, distinctive activity related to awareness of a change was observed in the theta band, following the onset of the change. Finally, we found some evidence in the beta band showing that changes may have been registered to a certain extent even when observers report not to have perceived them.

\section{Oscillatory Activity Related to the Detection of a Change}

After the onset of S2, that is, once the change has occurred, $\mathrm{CD}$, when compared with $\mathrm{CB}$ and NCC, was associated with more pronounced power enhancing at frontal, central, and parietal locations 300-600 msec post-S2 onset in a 3-5 Hz frequency range. No differences were observed between CB and NCC trials. This result is in agreement with previous studies linking theta activity at anterior locations to attention orienting toward target stimuli (Basar-Eroglu, Basar, Demiralp, \& Schurmann, 1992).

In addition, the latency and topography of this activity, along with its modulation by the detection of changes makes it consistent with the appearance of the P3 ERP component found here, which has been observed during conscious detection of visual changes (Pourtois et al., 2006; Eimer \& Mazza, 2005; Fernandez-Duque et al., 2003; Koivisto \& Revonsuo, 2003). The presence of oscillatory theta activity during P3 development has been found by several studies in the past (Yordanova \& Kolev, 1998; Basar-Eroglu et al., 1992). The higher amplitudes of P3 for CD relative 
to the other conditions and the lack of differences between NCC and CB have been linked to a postperceptual effect, probably reflecting decision and response selection stages or some form of memory updating (Polich \& Kok, 1995). Finally, this result is also congruent with fMRI findings indicating that conscious detection of visual changes involves activations on a frontal-parietal network commonly associated with selective attention (Beck et al., 2001). The role of this activity might be able to control the deployment of attention to the location of a change to allow further processing of the item that has changed (Pessoa \& Ungerleider, 2004).

\section{Oscillatory Activity Related to CB}

Differences in the oscillatory activity related to $\mathrm{CB}$ were patent as early as within the $500 \mathrm{msec}$ that followed the onset of the prechange display in the form of a transient power increase in the theta band $(3-5 \mathrm{~Hz})$ between 120 and $300 \mathrm{msec}$ post-S1 onset at parietal-occipital and occipital sites followed by a power suppression in the alpha band $(13-15 \mathrm{~Hz})$ in a time window from 300 to $500 \mathrm{msec}$ post-S1 at frontal, central, and parietal sites.

Early enhancements of theta activity following the presentation of a stimulus have been found in earlier studies (Tesche \& Karhu, 2000; Gevins, Smith, McEvoy, \& Yu, 1997) and have been related to stimulus perceptual processing as well as to memory (Jensen \& Tesche, 2002; Gevins et al., 1997; Klimesch, 1996) and attention (Green \& McDonald, 2008; Basar-Eroglu et al., 1992) processes. Links between theta activity and WM have been established by means of high-resolution EEG (Gevins et al., 1997) and coherence analyses (Sarnthein, Petsche, Rappelsberger, Shaw, \& von Stein, 1998). According to Klimesch (1996), theta frequency oscillations in occipital cortex would be involved in the maintenance of WM. Actually, theta oscillations at occipital cortical sites have been reported while subjects were holding items in WM over the course of a delay period (Raghavachari et al., 2001), and several studies have found that general increases in WM demands are sufficient for enhancing theta activity (Jensen \& Tesche, 2002; Tesche \& Karhu, 2000). However, it is known that there is a functional overlap in the mechanisms of WM and visual attention (Awh \& Jonides, 2001). Moreover, some authors have stated that the early theta power increase during WM tasks is not mainly related to encoding and/or retrieval but rather represents an EEG correlate of focused attention to target stimuli (Missonnier et al., 2006). Along those lines, there is some evidence showing strong evoked theta activity during neuropsychological paradigms involving focused attention (Basar-Eroglu et al., 1992). More recently, Green and McDonald (2008), employing a beamformer spatial filter to reconstruct the anatomical sources of low-frequency oscillations, found that theta enhanced in posterior areas during the first $300 \mathrm{msec}$ following the appearance of attention-directing cues, that is, in relation to voluntary attention control.
Results from Experiment 2 show that theta enhancements in response to the appearance of $\mathrm{S} 1$ are in our task modulated by WM load, so that the higher the WM demands are, the more pronounced the theta power enhancement is. Taking into account the functional overlap between attention and WM, higher WM demands would also impose the recruitment of more attentional resources. These results would support an interpretation of the theta band modulations found in Experiment 1, according to which $\mathrm{CB}$ trials were receiving more processing resources (i.e.: WM) than CD or NCC trials.

Results found in the alpha band point in the same direction. Early effects on theta activity were followed in the present experiment by power suppression in the alpha band, more pronounced for CB trials. Alpha power has been demonstrated to be inversely related to mental activity and has subsequently been used as an indirect measure of brain activation. According to Pfurtscheller and Lopes da Silva (Pfurtscheller \& Lopes da Silva, 1999), alpha suppression (in terms of event-related desynchronization, ERD) can be interpreted as a direct correlate of the amount of cortical activity involved in the processing of sensory or cognitive information (Pfurtscheller \& Klimesch, 1990). Thus, when the demand for processing resources increases, the size of the neural network would also increase, which would translate into enhanced or more widespread power suppression (Pfurtscheller \& Lopes da Silva, 1999).

The alpha generating system is linked to the thalamocortical networks responsible for WM (Klimesch, 1997). Alpha power suppression has been shown to increase with WM load (Gevins et al., 1997). However, it has been shown that the WM system includes two components (Smith \& Jonides, 1999): short-term storage, located in posterior brain regions, and attention-related executive processes, located in anterior areas, that operate on the contents of storage. Because increased alpha suppression was found at frontal and central areas but not at posterior sites, we could hypothesize that, even if the effects on alpha suppression were because of differences in WM load, the attention-related component of the WM would also be involved. In this regard, several EEG studies have described such alpha power suppressions following the onset of a stimulus under attention conditions in which WM is not involved (Fan et al., 2007). These results have found support in fMRI works that have correlated attentional modulations reflected by alpha power suppression with modulations in the activity of frontal-parietal cortices (Laufs et al., 2003), which are known to be attention modulating areas (Corbetta \& Shulman, 2002). The widely distributed alpha effect found here would be in agreement with those studies, both because of the time window and the scalp distribution of the effect, and could be interpreted as $\mathrm{CB}$ trials receiving a more intense recruitment of attention resources.

Taking into account evidences showing that both theta enhancements and alpha suppression are linked to a more pronounced recruitment of cognitive resources, it would 
be expected that the more pronounced these modulations are, the more in detail the prechange display would be encoded, and therefore, better performance would be achieved. However, this prediction did not find support neither in behavioral nor in electrophysiological data (see previous sections), and these modulations were in fact associated with CB (with a high statistical significance). One possible explanation for this paradox could be that these differences were related to the encoding strategy employed by the observers (see Schmiedt, Meistrowitz, Schwendemann, Herrmann, \& Basar-Eroglu, 2005). Because only a small number of items can be simultaneously attended (Pashler, 1988) and sometimes presentation times are insufficient for attending and encoding all the items in a scene, the strategy selected by the observers in a CD task may be critical for a change to be detected. This means that successful CD would not be determined by the amount of processing resources applied on a scene but by their application in the best possible way to ensure the adequate encoding of the scene. This may be particularly important in the present experiment for several reasons. First, the blank screen interposed between the two displays prevents the "transient" that usually accompanies a change from signaling its occurrence, which would facilitate its automatic detection, and makes it necessary to retain some information from the first display in visual STM (VSTM) to detect a subsequent change. Second, each display was present for only $133 \mathrm{msec}$. Given that the rate of consolidation in VSTM has been estimated in approximately 50 msec per item (Vogel, Woodman, \& Luck, 2006), the brief presentation time used in our experiment may not allow a thorough item-by-item encoding of the whole scene. Third, it should be noted that displays were composed of four items, a number bordering the limits of VSTM, which have been estimated in three to four elements in CD tasks (Luck \& Vogel, 1997). Taking these points into account, one could hypothesize that a strategy based on the intense recruitment of processing resources in an attempt to accurately encode the whole scene itemby-item would not be the most efficient one, whereas a strategy based on a more distributed (as opposed to a more intense) application of resources could favor the detection of changes. Distribution of resources would allow the composition of a more general image, encoded as only one figure instead of requiring separate encoding of each of the items. This strategy would, thus, impose fewer demands on WM, which would be reflected in less pronounced theta enhancements and alpha suppressions. The characteristics of the task itself seem to favor a strategy of this kind. Because the orientation of the items in our task was randomized for each prechange display, it is even possible that some trials were benefited by a prechange configuration that favors grouping, which would impose lower WM demands (Landman et al., 2003) and result in correct judgments being more likely. Similarly, differences in the oscillatory activity found in the $\mathrm{CB}$ condition could be because of these trials containing displays that impose higher WM demands on the observers, either because the displays do not favor such a grouping or because, regardless of the initial display configuration, subjects choose a strategy that involves item-by-item codification.

Among CB studies, only a few ERP works have addressed the issue of prechange activity (Pourtois et al., 2006; Koivisto \& Revonsuo, 2005) in the past and have proposed different electrophysiological prechange predictors of CB. Interestingly, although the markers proposed are different in each experiment, perhaps owing to differences in the designs of their respective tasks, both studies reached the conclusion that changes were more likely to be detected if attention was not focused on any particular location of the display but distributed more globally.

In summary, the effects found in the theta and alpha bands in Experiment 1 seem to reflect more intense recruiting of cognitive resources during the encoding of the prechange display in CB trials. This interpretation is supported by results in Experiment 2 showing that theta enhancements were in this task modulated by WM load. This intensive recruitment of resources could result from strategic decisions made by the subjects, seeking to ensure a certain rate of correct $\mathrm{CD}$, or from a prechange configuration that did not allow the employment of less demanding but more efficient memory strategies. Attention and memory mechanisms might be involved, and future research should be addressed to study in depth their specific contributions to the oscillatory activity during $\mathrm{CD}$.

\section{Implicit Detection of Changes}

Trials containing a change, whether detected or not, showed a higher power decrease than no-change trials in response to the onset of the change in a TF window from 15 to $17 \mathrm{~Hz}$ and between 118 and 180 msec post-S2 at frontal locations. The notion that changes may be detected without the involvement of conscious awareness is supported by similar findings in other domains. There is a rich literature showing that information can be represented and have an impact on behavior without such processing leading to awareness (Hannula, Simons, \& Cohen, 2005). Regarding CD, several studies provide support to the idea that change can be represented outside awareness (Fernandez-Duque \& Thornton, 2000; Smilek, Eastwood, \& Merikle, 2000). Only a few works, however, have found indications of implicit representation of changes other than those strictly behavioral. One of these exceptions comes from a study by Fernandez-Duque et al. (2003), who used a flicker paradigm in which the original and the changed image were cyclically repeated. These authors observed an anterior effect on the ERP waveform between 240 and 300 msec after a change onset, a result that has been recently replicated (Kimura et al., 2008) employing a one-shot paradigm, thus ruling out the possible amplification of the implicit effect because of repetition of stimuli (a possibility suggested by Pourtois et al., 2006). 
The analysis of the oscillatory activity performed in the present experiment allowed us to obtain further evidence on this point. More pronounced power suppressions in a frequency band between 15 and $17 \mathrm{~Hz}$ were observed at anterior locations for trials containing a change, whether it was detected or not, when compared with NCC trials. The latency in which this difference was found, along with its anterior scalp distribution, are coherent with the ERP evidences reported by those previous works. Our results may also be congruent with a recent fMRI study in which, employing a variant of the contextual cueing paradigm, evidence of the involvement of the anterior $\mathrm{pFC}$ in implicit processing of environmental changes was found (Pollmann \& Manginelli, 2009). As suggested by these authors, the role of this area may be to redirect attention to changes in our environment to allow their further processing, even in the absence of conscious awareness.

\section{Conclusions}

This study allowed us to identify different oscillatory patterns at distinct TF windows during a CD task. Postchange differences in the theta band, widely distributed over the scalp, proved to be explicitly associated with the aware detection of a change, rather than with a correct response or with the mere occurrence of a change. Prechange differences on posterior locations in the theta band and broadly distributed over the scalp in the alpha range correlated with $\mathrm{CB}$. Finally, we identified early postchange effects in the beta band on frontal locations that provide some evidence of implicit CD. Necessary future research may include the deliberate manipulation of attention and WM load to clearly understand their impact on the oscillatory activity in CB tasks and to shed further light on their involvement in the CD process.

\section{Acknowledgments}

This study was supported by two grants from the Spanish MEC (SEJ2007-61397 and PSI2010-21427).

Reprint requests should be sent to Álvaro Darriba, Department of Clinical Psychology and Psychobiology, Faculty of Psychology, Campus Sur S/N 15782, Santiago de Compostela, Galicia, Spain, or via e-mail: alvaro.darriba@usc.es.

\section{REFERENCES}

Awh, E., \& Jonides, J. (2001). Overlapping mechanisms of attention and spatial working memory. Trends in Cognitive Sciences, 5, 119-126.

Basar-Eroglu, C., Basar, E., Demiralp, T., \& Schurmann, M. (1992). P300-response: Possible psychophysiological correlates in delta and theta frequency channels. A review. International Journal of Psychophysiology, 13, 161-179.

Beck, D. M., Muggleton, N., Walsh, V., \& Lavie, N. (2006). Right parietal cortex plays a critical role in change blindness. Cerebral Cortex, 16, 712-717.
Beck, D. M., Rees, G., Frith, C. D., \& Lavie, N. (2001). Neural correlates of change detection and change blindness. Nature Neuroscience, 4, 645-650.

Bell, A. J., \& Sejnowski, T. J. (1995). An information-maximization approach to blind separation and blind deconvolution. Neural Computation, 7, 1129-1159.

Corbetta, M., \& Shulman, G. L. (2002). Control of goal-directed and stimulus-driven attention in the brain. Nature Reviews Neuroscience, 3, 201-215.

Delorme, A., \& Makeig, S. (2004). EEGLAB: An open source toolbox for analysis of single-trial EEG dynamics including independent component analysis. Journal of Neuroscience Methods, 134, 9-21.

Digiacomo, M. R., Marco-Pallarés, J., Flores, A. B., \& Gómez, C. M. (2008). Wavelet analysis of the EEG during the neurocognitive evaluation of invalidly cued targets. Brain Research, 1234, 94-103.

Eimer, M., \& Mazza, V. (2005). Electrophysiological correlates of change detection. Psychophysiology, 42, 328-342.

Fan, J., Byrne, J., Worden, M. S., Guise, K. G., McCandliss, B. D., Fossella, J., et al. (2007). The relation of brain oscillations to attentional networks. The Journal of Neuroscience, 27, 6197-6206.

Fernandez-Duque, D., Grossi, G., Thornton, I. M., \& Neville, H. J. (2003). Representation of change: Separate electrophysiological markers of attention, awareness, and implicit processing. Journal of Cognitive Neuroscience, 15, 491-507.

Fernandez-Duque, D., \& Thornton, I. M. (2000). Change detection without awareness: Do explicit reports underestimate the representation of change in the visual system? Visual Cognition, 7, 323-344.

Gevins, A., Smith, M. E., McEvoy, L., \& Yu, D. (1997). High-resolution EEG mapping of cortical activation related to working memory: Effects of task difficulty, type of processing, and practice. Cerebral Cortex, 7, 374-385.

Green, J. J., \& McDonald, J. J. (2008). Electrical neuroimaging reveals timing of attentional control activity in human brain. PLoS Biology, 6, e81. doi:10.1371/journal.pbio.0060081

Grimes, J. (1996). On the failure to detect changes in scenes across saccades. In K. Akins (Ed.), Perception (Vancouver studies in cognitive science) (Vol. 2, pp. 89-110). New York: Oxford University Press.

Gruber, W. R., Klimesch, W., Sauseng, P., \& Doppelmayr, M. (2005). Alpha phase synchronization predicts P1 and N1 latency and amplitude size. Cerebral Cortex, 15, 371-377.

Hannula, D. E., Simons, D. J., \& Cohen, N. J. (2005). Imaging implicit perception: Promise and pitfalls. Nature Reviews Neuroscience, 6, 247-255.

Jensen, O., \& Tesche, C. D. (2002). Frontal theta activity in humans increases with memory load in a working memory task. European Journal of Neuroscience, 15, 1395-1399.

Kiebel, S. J., Tallon-Baudry, C., \& Friston, K. J. (2005). Parametric analysis of oscillatory activity as measured with EEG/MEG. Human Brain Mapping, 26, 170-177.

Kimura, M., Katayama, J., \& Ohira, H. (2008). Event-related brain potential evidence for implicit change detection: A replication of Fernandez-Duque et al. (2003). Neuroscience Letters, 448, 236-239.

Klimesch, W. (1996). Memory processes, brain oscillations and EEG synchronization. International Journal of Psychophysiology, 24, 61-100.

Klimesch, W. (1997). EEG-alpha rhythms and memory processes. International Journal of Psychophysiology, 26, 319-340.

Klimesch, W., Sauseng, P., \& Hanslmayr, S. (2007). EEG alpha oscillations: The inhibition-timing hypothesis. Brain Research Reviews, 53, 63-88. 
Klimesch, W., Schack, B., Schabus, M., Doppelmayr, M., Gruber, W., \& Sauseng, P. (2004). Phase locked alpha and theta oscillations generate the P1-N1 complex and are related to memory performance. Cognitive Brain Research, 19, 302-316.

Koivisto, M., \& Revonsuo, A. (2003). An ERP study of change detection, change blindness, and visual awareness. Psychophysiology, 40, 423-429.

Koivisto, M., \& Revonsuo, A. (2005). Prechange event-related potentials predict change blindness in various attention conditions. NeuroReport, 16, 869-873.

Laloyaux, C., Destrebecqz, A., \& Cleeremans, A. (2006). Implicit change identification: A replication of Fernandez-Duque and Thornton (2003). Journal of Experimental Psychology: Human Perception and Performance, 32, 1366-1379.

Landman, R., Spekreijse, H., \& Lamme, V. A. (2003). Large capacity storage of integrated objects before change blindness. Vision Research, 43, 149-164.

Laufs, H., Kleinschmidt, A., Beyerle, A., Eger, E., Salek-Haddadi, A., Preibisch, C., et al. (2003). EEG-correlated fMRI of human alpha activity. Neuroimage, 19, 1463-1476.

Lee, T. W., Girolami, M., \& Sejnowski, T. J. (1999). Independent component analysis using an extended infomax algorithm for mixed subgaussian and supergaussian sources. Neural Computation, 11, 417-441.

Levin, D. T., \& Simons, D. J. (1997). Failure to detect changes to attended objects in motion pictures. Psychonomic Bulletin and Review, 4, 501-506.

Luck, S. J., \& Vogel, E. K. (1997). The capacity of visual working memory for features and conjunctions. Nature, 390, 279-281.

Missonnier, P., Deiber, M. P., Gold, G., Millet, P., Gex-Fabry Pun, M., Fazio-Costa, L., et al. (2006). Frontal theta event-related synchronization: Comparison of directed attention and working memory load effects. Journal of Neural Transmission, 113, $1477-1486$.

Oken, B. S., \& Chiappa, K. H. (1986). Statistical issues concerning computerized analysis of brainwave topography. Annals of Neurology, 19, 493-497.

O'Regan, J. K., Deubel, H., Clark, J. J., \& Rensink, R. A. (2000). Picture changes during blinks: Looking without seeing and seeing without looking. Visual Cognition, 7, 191-211.

O’Regan, J. K., Rensink, R. A., \& Clark, J. J. (1999). Change-blindness as a result of "mudsplashes". Nature, 398, 34.

Pashler, H. (1988). Familiarity and visual change detection. Perception \& Psychophysics, 41, 285-292.

Pessoa, L., \& Ungerleider, L. G. (2004). Neural correlates of change detection and change blindness in a working memory task. Cerebral Cortex, 14, 511-520.

Pfurtscheller, G., \& Klimesch, W. (1990). Topographical display and interpretation of event-related desynchronization during a visual-verbal task. Brain Topography, 3, 85-93.

Pfurtscheller, G., \& Lopes da Silva, F. H. (1999). Event-related EEG/MEG synchronization and desynchronization: Basic principles. Clinical Neurophysiology, 110, 1842-1857.
Phillips, W. A. (1974). On the distinction between sensory storage and short-term visual memory. Perception $E$ Psychophysics, 16, 368-373.

Polich, J., \& Kok, A. (1995). Cognitive and biological determinants of P300: An integrative review. Biological Psychology, 41, 103-146.

Pollmann, S., \& Manginelli, A. A. (2009). Early implicit contextual change detection in anterior prefrontal cortex. Brain Research, 1263, 87-92.

Pourtois, G., De Pretto, M., Hauert, C. A., \& Vuilleumier, P. (2006). Time course of brain activity during change blindness and change awareness: Performance is predicted by neural events before change onset. Journal of Cognitive Neuroscience, 18, 2108-2129.

Raghavachari, S., Kahana, M. J., Rizzuto, D. S., Caplan, J. B., Kirschen, M. P., Bourgeois, B., et al. (2001). Gating of human theta oscillations by a working memory task. Journal of Neuroscience, 21, 3175-3183.

Rensink, R. A. (2000). The dynamic representation of scenes Visual Cognition, 7, 17-42.

Rensink, R. A., O’Regan, J. K., \& Clark, J. J. (1997). To see or not to see: The need for attention to perceive changes in scenes. Psychological Science, 8, 368-373.

Sarnthein, J., Petsche, H., Rappelsberger, P., Shaw, G. L., \& von Stein, A. (1998). Synchronization between prefrontal and posterior association cortex during human working memory. Proceedings of the National Academy of Sciences, U.S.A., 95, 7092-7096.

Schmiedt, C., Meistrowitz, A., Schwendemann, G., Herrmann, M., \& Basar-Eroglu, C. (2005). Theta and alpha oscillations reflect differences in memory strategy and visual discrimination performance in patients with Parkinson's disease.

Neuroscience Letters, 388, 138-143.

Simons, D. J. (2000). Current approaches to change blindness. Visual Cognition, 7, 1-15.

Smilek, D., Eastwood, J. D., \& Merikle, P. M. (2000). Does unattended information facilitate change detection? Journal of Experimental Psychology: Human Perception and Performance, 26, 480-487.

Smith, E. E., \& Jonides, J. (1999). Storage and executive processes in the frontal lobes. Science, 283, 1657-1661.

Tallon-Baudry, C., \& Bertrand, O. (1999). Oscillatory gamma activity in humans and its role in object representation. Trends in Cognitive Sciences, 3, 151-162.

Tesche, C. D., \& Karhu, J. (2000). Theta oscillations index human hippocampal activation during a working memory task. Proceedings of the National Academy of Sciences, U.S.A., 97, 919-924.

Vogel, E. K., Woodman, G. F., \& Luck, S. J. (2006). The time course of consolidation in visual working memory. Journal of Experimental Psychology: Human Perception and Performance, 32, 1436-1451.

Yordanova, J., \& Kolev, V. (1998). Single-sweep analysis of the theta frequency band during an auditory oddball task. Psychophysiology, 35, 116-126. 